\title{
Técnica histoquímica aplicada ao tecido ósseo desmineralizado e parafinado para 0 estudo do osteócito e suas conexões
}

\author{
Histochemical tecnique for osteocyte and its connections study in descalcified and paraffined bone tissue \\ Natália de Melo Ocarino'; Mardelene Geísa Gomes²; Eliane Gonçalves de Melo³; Rogéria Serakides ${ }^{4}$
}

\begin{abstract}
unitermos resumo
Osteócito

Histoquimica

Conexöes

Osso

O osteócito vem sendo alvo de pesquisas recentes. A avaliação in situ de sua morfologia, da atividade e das características de suas conexões é difícil, portanto é realizada apenas com técnicas avançadas. Devido à importância desse tipo celular na manutenção da matriz óssea, este estudo propõe uma técnica de coloração pela prata como alternativa para o estudo do osteócito e suas conexões em tecido ósseo desmineralizado e parafinado. Cortes de $4 \mu \mathrm{m}$ do fêmur de ratas foram desmineralizados, desparafinados em xilol e hidratados em concentrações decrescentes de álcool etílico (ETOH) e água miliQ. Para a impregnação foram utilizadas soluções de nitrato de prata a $50 \%$ e de ácido fórmico a $1 \%$ com $2 \%$ de gelatina microbiológica em estufa a $40^{\circ} \mathrm{C}$. Essa técnica permite visualizar facilmente as bordas lacunares dos osteócitos e suas conexões, proporcionando uma alternativa simples e eficaz para o estudo da morfologia desse tipo celular até então ainda não proposta com essa finalidade.
\end{abstract}

The osteocyte has been the subject of recent research; however the in situ evaluation of its morphology, activity and connection characteristics is difficult and has been performed solely through advanced techniques. Due to the importance of this type of cell in the maintenance of the bone matrix, this study proposes a technique of silver staining as an alternative for the study of the osteocyte and its connections in demineralized and paraffined bone tissue. Cuts of $4 \mu \mathrm{m}$ from the femur of female rats were de-mineralized, deparaffined in xylol and hydrated in decreasing concentrations of ETOH and miliQ water. For the impregnation, solutions of silver nitrate at $50 \%$ and formic acid at $1 \%$ with $2 \%$ microbiological gel were used and incubated at $40^{\circ} \mathrm{C}$. This technique allows the easy visualizing of the osteocytes lacunae edges and its connections, offering a simple and efficient alternative to the study of this type of cellular morphology, so far not proposed with this purpose.
O osteócito é o tipo celular presente em maior número no tecido ósseo maduro ${ }^{(11)}$ e se encontra alojado em lacunas no seu interior ${ }^{(5,11)}$. Essas células se comunicam entre si e com os osteoblastos por meio de uma rede de conexões formada por processos intracanaliculares $(4,9,11)$. Essas conexões têm a função de promover a passagem de metabólitos, íons e moléculas sinalizadoras intracelulares importantes para a manuten-

1. Médica veterinária; doutoranda em Medicina Veterinária no Departamento de Clínica e Cirurgia da Escola de Veterinária da Universidade Federal de Minas Cerais (UFMG).

2. Bióloga; mestranda em Patologia no Departamento de Patologia Ceral do Instituto de Ciências Biológicas da UFMG.

3. Médica veterinária; doutora; professora-adjunta do Setor de Cirurgia do Departamento de Clínica e Cirurgia da Escola de Veterinária da UFMG.

4. Médica veterinária; doutora; pesquisadora do Conselho Nacional de Desenvolvimento Científico e Tecnológico (CNPq); professora-adjunta do Setor de Patologia do Departamento de Clínica e

Cirurgia da Escola de Veterinária da UFMC.

Trabalho realizado com auxílio da Fundação de Amparo à Pesquisa do Estado de Minas Cerais (FAPEMIG - CAC134/02), baseado na dissertação Atividade Física no Tratamento da Osteoporose: Histomorfometria do Esqueleto Axial e Apendicular de Ratas, defendida em outubro de 2004 na Escola de Veterinária da UFMG. 
ção da matriz óssea ${ }^{(3)}$. Muitas funções têm sido atribuídas aos osteócitos, como manutenção e viabilidade do tecido ósseo ${ }^{(11)}$ e reabsorção da matriz e dos minerais pela osteólise osteocítica, mantendo constantes os níveis de cálcio extracelulares $^{(2)}$. Outra função importante e que vem sendo amplamente estudada é a participação do osteócito como célula responsável por traduzir a força mecânica imposta ao osso em sinais bioquímicos que regulam o turnover ósseo ${ }^{(3,}$ 6). Por ser considerada uma célula multifuncional envolvida nos processos que regulam tanto a formação quanto a reabsorção ósseas, o osteócito tem ganho cada vez mais importância na osteologia ${ }^{(1,4,8,11)}$. Mas por ser uma célula que se localiza no interior do tecido ósseo mineralizado, a avaliação in situ de sua morfologia, atividade e características de suas conexões é difícil ${ }^{(11)}$ e vem sendo realizada por técnicas mais avançadas, como a microscopia eletrônica(8), o que requer o preparo do material a ser analisado de forma específica. O objetivo do presente estudo é propor uma técnica histoquímica, que até então nunca havia sido proposta com tal finalidade, a ser aplicada ao tecido ósseo desmineralizado e parafinado, para o estudo do osteócito e de suas conexões.

Foram utilizados fêmures de ratas Wistar adultas normais e com osteoporose advindos do estudo prévio realizado por Ocarino $^{(7)}$. A razão pela qual se testou a coloração em tecido ósseo normal e com osteoporose foi demonstrar que essa técnica, além de propiciar a visualização das conexões dos osteócitos, permite identificar satisfatoriamente alterações nessas conexões, tal como já demonstrado previamente pela microscopia eletrônica ${ }^{(4,11)}$.

O fêmur foi fixado em formalina neutra e tamponada, com fosfato a $10 \%$, descalcificado em ácido fórmico a $10 \%$, tamponado com citrato de sódio para pH 4,5 sob vácuo moderado por 14 dias. Após completa descalcificação, constatada por imagem radiológica obtida de aparelho de microrradiografia, o osso foi processado pela técnica de inclusão em parafina e submetido a impregnação pela prata para visualização das conexões entre os osteócitos. A impregnação pela prata foi realizada em cortes histológicos de $4 \mu \mathrm{m}$ desparafinados em xilol e hidratados em concentrações decrescentes de álcool etílico por 5 minutos em cada álcool (álcool absoluto a 90\%, 80\%, 70\%). A hidratação foi concluída com as lâminas em água miliQ por 10 minutos. Para a impregnação foram utilizadas duas soluções distintas. A primeira, composta por solução aquosa de nitrato de prata a $50 \%$ armazenada em frasco âmbar e em geladeira, e a segunda, por solução de ácido fórmico a $1 \%$ com $2 \%$ de gelatina microbiológica incolor.
Em cada corte histológico foram adicionadas as soluções 1 e 2 na proporção de 1:1. Em seguida as lâminas foram incubadas a $40^{\circ} \mathrm{C}$ em câmara úmida por 20 minutos. Após a impregnação, as lâminas foram lavadas em água miliQ por 10 minutos, desidratadas em concentrações crescentes de álcool etílico absoluto(70\%, 80\%, 90\%) por 5 minutos e montadas com lamínulas e bálsamo do Canadá natural. Essa técnica foi adaptada da proposta por Ploton et al.(10), utilizada para marcar regiões organizadoras de nucléolo argentafins em neoplasias e que até então nunca havia sido proposta como técnica de coloração para a avaliação morfológica dos osteócitos e de suas conexões.

No tecido ósseo das ratas normais, as conexões dos osteócitos, impregnadas de preto, apresentaram-se longas, numerosas e altamente conectadas, formando, assim, uma grande rede de conexões entre as células (Figura 1A). Já nos animais com osteoporose, as conexões mostravam-se menos numerosas, curtas, tortuosas e pouco conectadas umas às outras (Figura 1B). As bordas lacunares dos osteócitos também foram impregnadas pela prata, o que permitiu avaliar melhor a atividade dos osteócitos, uma vez que as características das bordas lacunares estão relacionadas com o estado funcional desta célula ${ }^{(8)}$. Resultados idênticos foram obtidos com inúmeras repetições da técnica. As alterações nas conexões dos osteócitos de tecido ósseo osteoporótico observadas neste estudo foram semelhantes às descritas utilizando-se a microscopia eletrônica ${ }^{(11)}$, o que confirma a eficiência da técnica. Além do mais, é importante ressaltar que colorações rotineiras, como hematoxilina e eosina entre as várias outras que constam nos roteiros de técnicas histológicas de coloração, não permitem visualizar as conexões dos osteócitos, tal como demonstrado no presente estudo.

Conclui-se que essa técnica histoquímica simples pode ser aplicada ao tecido ósseo desmineralizado e parafinado para o estudo eficaz do osteócito e de suas conexões.

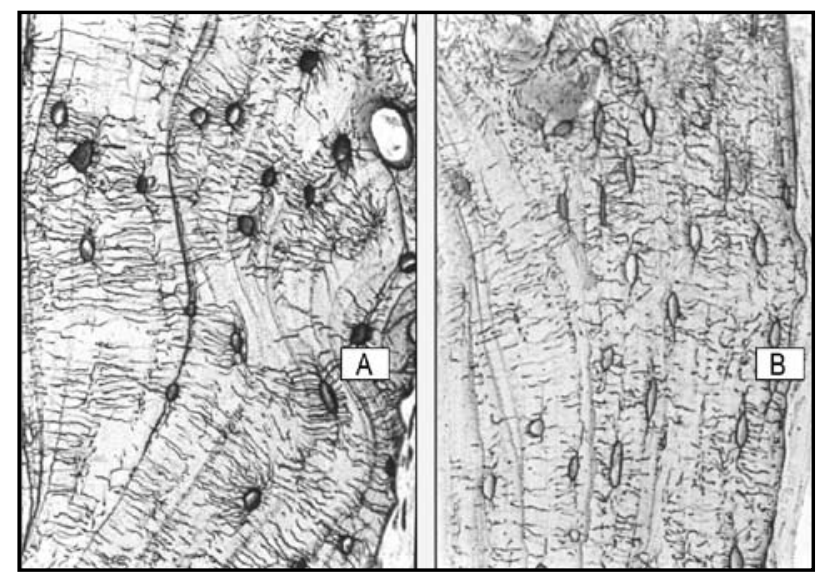

Figura 1 


\section{Referências}

I. BONEWALD, L. F. Osteocyte biology: its implications for osteoporosis. J Musculoskelet Neuronal Interact, v. 4, n. I, p. 101-4, 2004.

2.CILLINAME, D. M.The role of osteocytes in bone regulation: mineral homeostasis versus mechanoreception. J Musculoskelet Neuronal Interact, v. 2, p. 242-4, 2002.

3. CHERIAN, P.P.et al. Effects of mechanical strain on the function of gap junctions in osteocytes are mediated through the prostaglandin EP2 receptor.J Biol Chem, v. 278, p. 43।46-56, 2003.

4. COLOPY, S. A. et al. Response of osteocyte syncytium adjacent to and distant from linear microcracks during adaptation to cyclic fatigue loading. Bone, v. 35, p. 88I-9I, 2004.

5. COWIN, S. C. Mechanosensation and fluid transport in living bone.J Musculoskelet Neuronal Interact, v. 2, n. 3, p. 256-60, 2002.

6. NOMURA, S.; YAMAMOTO, T. T. Molecular event caused by mechanical stress in bone. Matrix Biol, v. 19, p. 91-6, 2000.
7. Ocarino, N. M. Atividade física no tratamento da osteoporose: histomorfometria do esqueleto axial e apendicular de ratas. 2004. Dissertação (mestrado) - Patologia. Universidade Federal de Minas Gerais, Belo Horizonte.

8. PALUMBO, C. et al. Osteocyte-osteoclast morphological relationships and the putative role of osteocytes in bone remodeling. J Musculoskelet Neuronal Interact, v. I, n. 4, p. 327-32, 2001.

9. PARFITT, A. M. Life history os osteocytes: relationship to bone age, bone remodeling, and bone fragility. J Musculoskelet Neuronal Interact, v. 2, n. 6, p. 499-500, 2002.

10. PLOTON, D. et al. Improvement in the staining and in the visualization of the argyrophilic proteins of the nucleolar organizer region at the optical level. Histochemical J, v. 18, p. 5-14, 1986.

I I. TATE, M. K. et al.The osteocytes. J Biochem Cell Biol, v. 36, p. $1-8,2004$. 